\title{
Orthostatic Hypotension and Antiparkinsonian Drugs: A Systematic Review and Meta-analysis
}

\author{
Danielle, Nimmons, MRes' ${ }^{\circ}$, Cini Bhanu, MRes', Mine Orlu, $\mathbf{P h D}^{2}$, \\ Anette Schrag, PhD $^{3}$, and Kate Walters, PhD' $^{\prime}$
}

\begin{abstract}
Background: Orthostatic hypotension $(\mathrm{OH})$ is multifactorial in Parkinson's disease (PD). Antiparkinsonian medication can contribute to $\mathrm{OH}$, leading to increased risk of falls, weakness and fatigue. Methods: We conducted a systematic review and meta-analysis of randomised controlled trials (RCTs) of antiparkinsonian drugs associated with $\mathrm{OH}$ as an adverse effect, compared to placebo. We searched EMBASE, MEDLINE and Web of Science databases until November 2020. Analysis used fixed-effects models and the GRADE tool to rate quality of evidence. Meta-analysis was performed if 3 or more studies of a drug group were available. Results: Twenty-one RCTs including 3783 patients were included comparing 6 PD drug groups to placebo (MAO-B inhibitors, dopamine agonists, levodopa, COMT inhibitors, levodopa and adenosine receptor antagonists). $\mathrm{OH}$ was recorded as an adverse event or measurement of vital signs, without further specification on how this was defined or operationalised. Meta-analysis was performed for MAO-B inhibitors and dopamine agonists, as there were 3 or more studies for these drug groups. In this analysis, compared with placebo, neither MAO-B inhibitors or dopamine agonists were associated with increased risk of OH, (OR 2.28 [95\% Cl:0.8I6.46]), (OR I.39 [95\% Cl:0.97-1.98]). Conclusions: Most studies did not specifically report $\mathrm{OH}$, or reporting of $\mathrm{OH}$ was limited, including how and when it was measured. Furthermore, studies specifically reporting $\mathrm{OH}$ included participants that were younger than typical PD populations without multimorbidity. Future trials should address this, for example,, by including individuals over the age of 75 , to improve estimations of how antiparkinsonian medications affect risk of $\mathrm{OH}$.
\end{abstract}

\section{Keywords}

orthostatic hypotension, Parkinson's disease, medication

\section{Introduction}

Orthostatic hypotension $(\mathrm{OH})$ is common in Parkinson's disease (PD), with a prevalence ranging between 9.6$64.9 \%{ }^{1}$ This wide range reflects heterogeneity of studies, differences in $\mathrm{OH}$ definition used and population included. The classical definition of $\mathrm{OH}$ is 'a sustained reduction of at least $20 \mathrm{mmHg}$ of systolic blood pressure (BP) and/or $10 \mathrm{mmHg}$ of diastolic BP within 3 minutes of standing or head-up tilt-table testing', 2 However, $\mathrm{OH}$ can be difficult to detect, as symptoms such as dizziness, sweating and light headedness are non-specific or may be absent.

The prevalence of $\mathrm{OH}$ increases with age ${ }^{3}$ and can be divided into 3 categories that may co-exist: drug-induced, related to depletion of intravascular volume and neurogenic. ${ }^{4}$
In $\mathrm{PD}$, neurogenic $\mathrm{OH}$ is a consequence of autonomic dysfunction, which is mainly a result of cardiac sympathetic denervation and reduced activation of noradrenergic pathways. Parkinson's disease patients with $\mathrm{OH}$ experience worsening of $\mathrm{OH}$ over time that correlates with disease duration. $\mathrm{OH}$ also affects quality of life and

\footnotetext{
'Centre for Ageing Population Studies, Research Department of Primary Care and Population Health, UCL, UK

${ }^{2}$ UCL School of Pharmacy, UCL, UK

${ }^{3}$ Department of Neurology, Institute of Neurology, UCL, UK
}

\section{Corresponding Author:}

Danielle Nimmons, Research Department of Primary Care and Population Health, UCL, Rowland Hill Street, London NW3 2PF, UK. Email: d.nimmons@ucl.ac.uk 
increases the risk of falls, weakness, fatigue ${ }^{3}$ and cognitive impairment. ${ }^{5}$

Previous studies also reported associations between $\mathrm{OH}$ and PD medications, complicating management of PD. This includes levodopa,${ }^{6-8}$ dopamine agonists ${ }^{9}$ and monoamine oxidase inhibitors. ${ }^{10}$ Studies have also reported that patients diagnosed with $\mathrm{OH}$ before starting these treatments are likely to experience a worsening of hypotension when these drugs are started. ${ }^{11}$ Furthermore, when these medications are used in combination with each other or with other medications, $\mathrm{OH}$ can be potentiated. However, one systematic review and meta-analysis of randomised controlled trials (RCTs) comparing tolerability and safety of ropinirole in monotherapy and adjuvant therapy with levodopa vs other dopamine agonists found cabergoline to be the only dopamine agonist associated with a higher risk of $\mathrm{OH}$ compared to placebo. ${ }^{12}$

There are few systematic reviews or meta-analyses exploring the association between $\mathrm{OH}$ and antiparkinsonian medications. However, this is important to understand as it may aid clinical decision making in PD. Observational studies can be subject to unmeasured confounding, including confounding by indication, compared to RCTs. ${ }^{13}$ Therefore, the aim of this systematic review and metaanalysis was to understand the association between $\mathrm{OH}$ and antiparkinsonian drugs compared to placebo, using randomised controlled trial evidence.

\section{Methods}

\section{Study Design}

A systematic review and meta-analysis of randomised controlled trials was conducted following the Preferred Reporting Items for Systematic Reviews and Meta Analyses (PRISMA) guidelines. ${ }^{14}$ This review was conducted as part of a broader review exploring drugs causing $\mathrm{OH}$, and a protocol was registered on PROSPERO (CRD42020168697). ${ }^{15}$ Parkinson's disease was explored separately, since mechanisms of $\mathrm{OH}$ and demographics are potentially different in this population compared to the general population. Ethics approval was not warranted.

\section{Data Sources and Searches}

The search strategies were developed with an information scientist (Appendix 1) without language restrictions and included a systematic literature search of EMBASE, MEDLINE and Web of Science from inception to November 23, 2020. The search strategy included drug terms, individual drug names (identified by the international non-proprietary name (INN) in the British National Formulary (BNF) and U.S. National Library of Medicine) and accounted for drugs with name changes. ${ }^{16}$ A macro was developed to automate searches and facilitate the search strategy (Pulover's macro creator version 5.2.8). Reference lists of eligible reports were reviewed, and authors contacted to supplement incomplete reports of the original papers.

\section{Eligibility Criteria}

Included studies were RCTs comparing any drug used in the management of motor features of PD with placebo, reporting incident $\mathrm{OH}$ as an adverse effect or outcome in adults ( $\geq 18$ years). Studies comparing a drug to another drug were excluded, and if the population had a diagnosis other than PD (e.g. depression or restless legs syndrome). This was because the participant characteristics, such as age, were very different in these populations.

\section{Study Selection}

One reviewer (CB) screened all titles, abstracts and fulltext articles reporting potentially eligible studies. A second reviewer (DN) screened 10\% of titles and abstracts, and 3 reviewers (DN, HH and SM) screened $10 \%$ of all full-text articles. We calculated the Cohen's $\kappa$ statistic to assess interrater agreement regarding eligibility. Disagreements were arbitrated by a third reviewer (KW) when necessary. An online systematic review software (Rayyan, QCRI) facilitated literature screening. ${ }^{17}$

\section{Data Extraction}

DN used a data extraction table for included studies, including patient demographics, length and severity of PD, drug characteristics, adjunct PD medication permitted, number of adverse events and method of reporting $\mathrm{OH}$ Reporting of $\mathrm{OH}$ incidence was grouped into categories following expert consensus:

- 'measured and validated' (a documented postural BP examination performed using a threshold of $\geq 20 \mathrm{mmHg}$ systolic and/or $\geq 10 \mathrm{mmHg}$ diastolic drop);

- 'Lying \&Standing BP measured' or 'Semisupine \&Standing BP measured' (a documented postural BP examination performed without a specified threshold);

- 'BP measured' (a documented BP examination only but implied as postural since the study reports $\mathrm{OH}$ );

- 'physical examination';

- 'vital signs recorded';

- 'adverse events noted';

- 'symptom report'.

We included all RCTs in the meta-analysis that compared drug to placebo and reported $\mathrm{OH}$ in any of the above categories. 


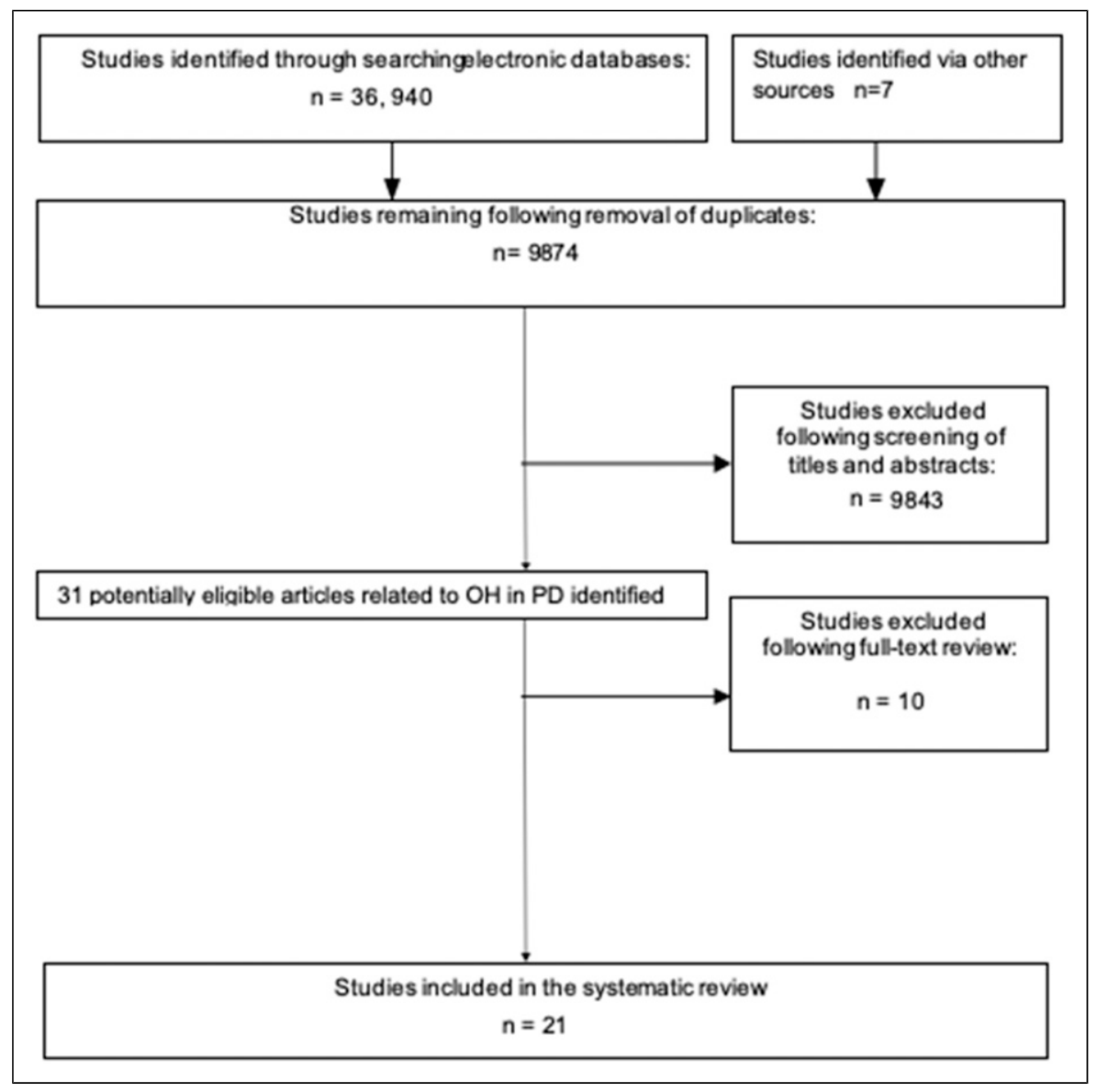

Figure I. Results of the searches.

\section{Risk of Bias Assessment}

DN assessed all included articles for risk of bias using the revised Cochrane risk of bias tool for randomised trials (RoB 2$),{ }^{18}$ and CB independently assessed $20 \%$ of articles. Studies were assigned an overall score: 'low', 'some concerns' or 'high'.

\section{Data Synthesis, Analysis and Quality of Evidence}

All RCTs comparing drug vs placebo with reporting of $\mathrm{OH}$ were grouped according to drug class, and results were pooled if 3 or more studies of a drug group were available. Further subgroup analysis was done according to individual drug. We estimated summary odds ratios for incident $\mathrm{OH}$ as a dichotomous outcome using fixed-effects MantelHaenszel statistics. Heterogeneity was assessed using the $\chi 2$ test and $\mathrm{I}^{2}$ statistic with an $\mathrm{I}^{2}>50 \%$ representing substantial heterogeneity. We used Review Manager software version 5.4 (Cochrane). The Grading of Recommendations Assessment, Development and Evaluation was used to summarise the quality of evidence. ${ }^{19}$

\section{Results}

\section{Study Characteristics}

36940 citations were identified by the search related to $\mathrm{OH}$ as a side effect in any drug (not restricted to PD, as part of the original searches ${ }^{15}$ ). Out of these, 31 potentially eligible articles were retrieved in full-text related specifically to $\mathrm{OH}$ in PD (Figure 1). Ten full texts were excluded; as they were related to drugs not used to treat PD motor features or investigated drugs used to primarily treat other conditions in non-PD populations. There was substantial agreement between reviewers at the title and abstract stage $(\kappa=.88)$ and full-text review stage $(\kappa=.81)$.

Overall, 21 double-blind RCTs (comprising 3783 patients) conducted between 1983 and 2020 were included. ${ }^{20-40}$ They reported on incident $\mathrm{OH}$, comparing 6 PD drug groups to placebo (MAO-B inhibitors, dopamine agonists, levodopa, COMT inhibitors, levodopa, amantadine and adenosine receptor antagonists). There were 3 or more studies for 2 PD drug groups, which were therefore eligible for meta-analysis (MAO-B inhibitors 


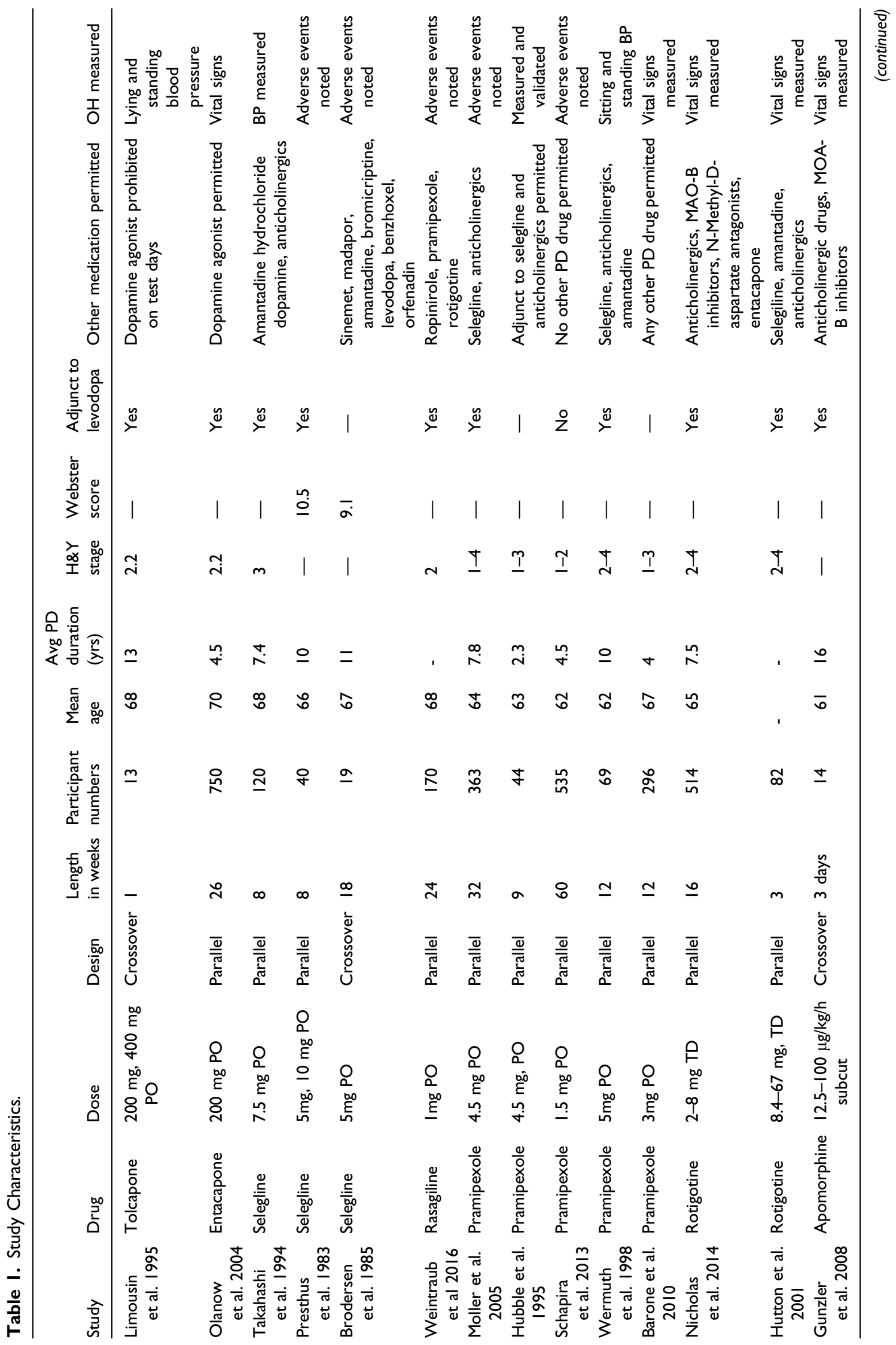




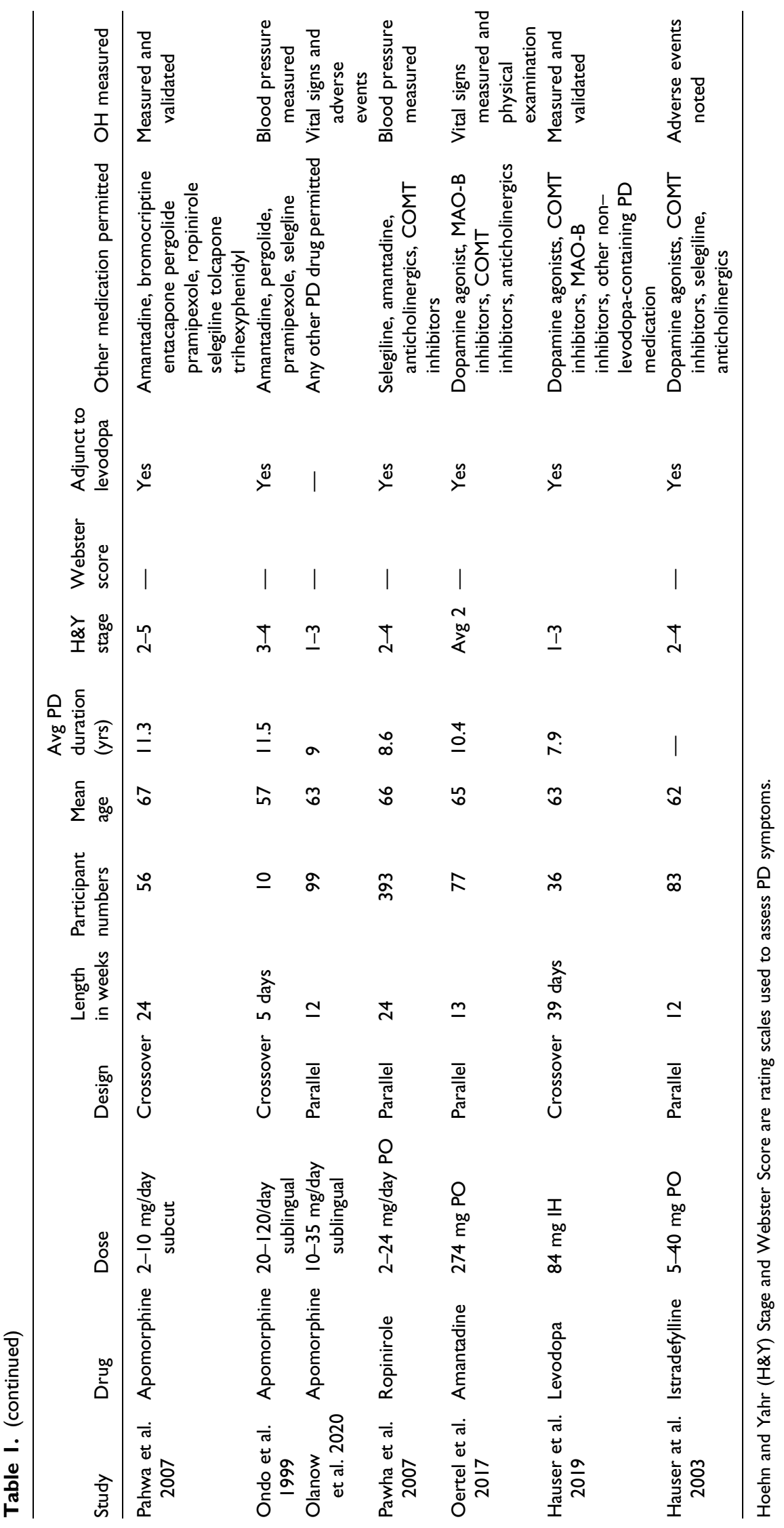


Table 2. Orthostatic Hypotension Reporting in the Studies.

Way in which $\mathrm{OH}$ was measured Number of studies

Measured and validated 3

'Lying and standing' or 'semisupine and standing' BP measured 2

Blood pressure measured

Vital signs recorded

Adverse events noted

and dopamine agonists). Table 1 summarises the characteristics of the included studies.

Overall, only 3 studies had a reported 'measured and validated' $\mathrm{OH}$ outcome according to our criteria, defined as a reduction in systolic BP of $\geq 20 \mathrm{mmHg}$, and/or a reduction in diastolic $\mathrm{BP}$ of $\geq 10 \mathrm{mmHg}$ after standing from a semisupine position..$^{27,34,38}$ The recording of the outcome as an adverse event or measurement of vital signs were the most common method in which $\mathrm{OH}$ was recorded, without further specification on how this was defined or operationalised within the study (Table 2). Note Olanow et al. 2020 measured vital signs and also noted adverse events.

Sixteen out of 21 studies investigated the study drug as an adjunct to levodopa and 20/21 permitted the use of other PD medications. Only one study investigated the drug as monotherapy compared to placebo and did not permit the use of any other PD medication. ${ }^{28}$

\section{Risk of Bias and Quality of Evidence}

According to Rob 2, 6/21 studies had an overall 'low' risk of bias and 15/21 studies scored either 'some concern' or 'high'. This was mostly due to studies not describing the method of measuring $\mathrm{OH}$ and lacking a pre-specified plan for analysis (Appendix 2).

The GRADE judgements are outlined in Appendix 3 for drug groups with 3 or more studies suitable for metaanalysis (MAO-B Inhibitors and dopamine agonists). The certainty of evidence varied. It was low for dopamine agonists and very low for MAO-B Inhibitors. This was due to high risk of bias in many studies, and it was unclear how and when $\mathrm{OH}$ was measured.

\section{MAO-B Inhibitors}

Four RCTs investigated MAO-B inhibitors. ${ }^{22-25} 3$ RCTs investigated selegiline $(5-10 \mathrm{mg})$ and $1 \mathrm{rasagiline}(1 \mathrm{mg})$. Three were parallel and 1 was a crossover trial. Participant numbers ranged from 19 to 322 and mean age 67 years. Study duration ranged between 8 and 24 weeks. The average disease duration was not available for Weintraub et al., but for the remaining 3 studies, it was 8.4 years. In the study conducted by Takahashi et al., $\mathrm{OH}$ was determined by measuring $\mathrm{BP}$ at visits, while in the others adverse events were noted. In the meta-analysis, MAO-B Inhibitors for treatment of PD were not associated with an increased risk of $\mathrm{OH}$ compared with placebo (OR 2.28 [95\% CI .81-6.46]) (Figure 2).

\section{Dopamine Agonists}

Thirteen RCTs investigated the association of dopamine agonists with $\mathrm{OH}$ in $\mathrm{PD}$ :

- Pramipexole $\mathrm{n}=5^{26-30}$

- Rotigotine $n=2^{31,32}$

- Apomorphine $n=4^{33-35,40}$

- Ropinirole $\mathrm{n}=1^{36}$

- Amantadine $\mathrm{n}=1^{37}$

The meta-analysis of these studies did not demonstrate an increased risk of $\mathrm{OH}$ with dopamine agonists treatment compared with placebo (OR 1.39 [95\% CI .97-1.98]) (Figure 3).

\section{Pramipexole}

Five parallel RCTs investigated pramipexole $1.5-5 \mathrm{mg}$. Participant numbers ranged from 44 to 535 . The mean age was 64 years and mean disease duration was 5.5 years. ${ }^{26-30}$ $\mathrm{OH}$ was determined in a range of ways (Table 1) and study duration ranged between 9 and 50 weeks. Of interest, the study that used a measured and validated method for assessing BP found all patients had at least 1 episode of $\mathrm{OH}$ during the study period. ${ }^{27}$ However, only $7 / 28$ in the treatment group (25\%) and 5/27 in the placebo group (18.5\%) experienced symptoms - these did not require any treatment, nor were they dose limiting. Meta-analysis showed pramipexole did not demonstrate an association with an increased risk of $\mathrm{OH}$, compared with placebo (OR 1.33 [95\% CI .85-2.07]) (Figure 4).

\section{Apomorphine}

Three crossover and one parallel RCT investigated apomorphine, with study periods ranging between 3 days and 24 weeks with 10-99 participants, mean age 63 years and disease duration was 10.4 years. ${ }^{33-35,40}$ In 2 studies, vital signs were recorded, ${ }^{33,40}$ while BP was measured in 


\begin{tabular}{|c|c|c|c|c|c|c|c|c|c|c|}
\hline Study or Subgroup & \multicolumn{2}{|c|}{ Experimental } & \multicolumn{2}{|c|}{ Placebo } & Weight & $\begin{array}{c}\text { Odds Ratio } \\
\text { M-H, Fixed, } 95 \% \mathrm{Cl}\end{array}$ & Year & \multicolumn{3}{|c|}{$\begin{array}{c}\text { Odds Ratio } \\
\text { M-H, Fixed, } 95 \% \mathrm{Cl}\end{array}$} \\
\hline Presthus 1983 & 3 & 15 & 3 & 11 & $53.4 \%$ & $0.67[0.11,4.17]$ & 1983 & +1 & & \\
\hline Brodersen 1985 & 1 & 19 & 0 & 19 & $8.9 \%$ & $3.16[0.12,82.64]$ & 1985 & & & \\
\hline Takahashi 1994 & 4 & 60 & 1 & 52 & $19.3 \%$ & $3.64[0.39,33.67]$ & 1994 & & & \\
\hline Weintraub 2016 & 5 & 86 & 1 & 84 & $18.4 \%$ & $5.12[0.59,44.82]$ & 2016 & & & \\
\hline Total $(95 \% \mathrm{Cl})$ & & 180 & & 166 & $100.0 \%$ & $2.28[0.81,6.46]$ & & & & \\
\hline Total events & 13 & & 5 & & & & & & & \\
\hline \multicolumn{8}{|c|}{$\begin{array}{l}\text { Heterogeneity: } \mathrm{Chi}^{2}=2.47, \mathrm{df}=3(\mathrm{P}=0.48) ; \mathrm{I}^{2}=0 \% \\
\text { Test for overall effect: } Z=1.55(P=0.12)\end{array}$} & $0.01 \quad 0.1 \quad 1$ & $\begin{array}{c}10 \\
\text { Favours [control] }\end{array}$ & 100 \\
\hline
\end{tabular}

Figure 2. Forest plot with all MAO-B inhibitors studies.

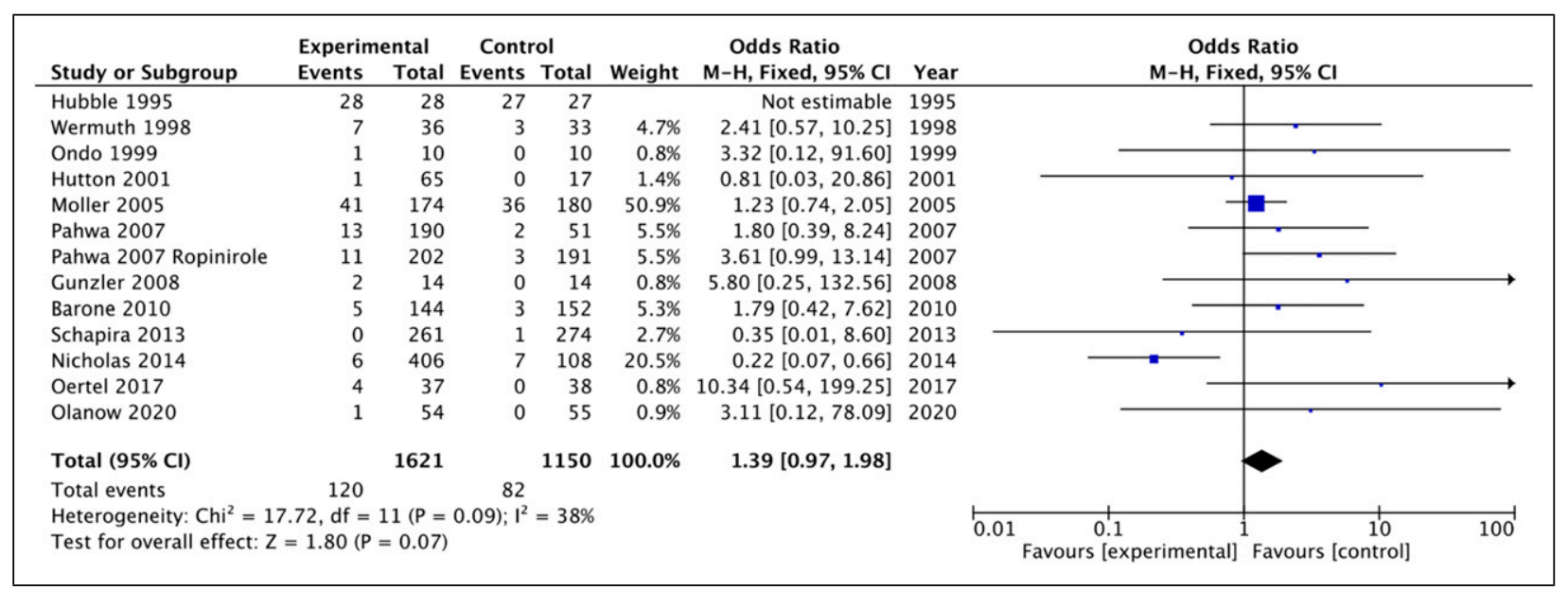

Figure 3. Forest plot with all dopamine agonist studies.

another, ${ }^{35}$ and 1 study described a postural BP examination performed using a threshold of $\geq 20 \mathrm{mmHg}$ systolic $1 \geq 10 \mathrm{mmHg}$ diastolic drop. ${ }^{34}$ Meta-analysis did not demonstrate an association of apomorphine with an increased risk of $\mathrm{OH}$, compared with placebo (OR 2.49 [95\% CI .76-8.12]) (Figure 5).

\section{Rotigotine}

Two parallel RCTs investigated rotigotine at doses of 2 to $76 \mathrm{mg}$ in participant numbers ranging from $82-514$ and study duration ranging between 3 and 16 weeks. ${ }^{31,32}$ Nicholas et al. reported disease duration and age of participants; and the average was 7.5 years and 65 years respectively. In both studies, $\mathrm{OH}$ was determined by measuring vital Figure 2 signs at study visits. Hutton et al. found the incidence of $\mathrm{OH}$ events was $2 \%$ in the treatment group $(1 / 65)$ compared to $0 \%$ in the placebo group $(0 / 17){ }^{32}$ While Nicholas et al. found the incidence of $\mathrm{OH}$ events was $1 \%$ in the treatment group (6/406) compared to $6 \%$ in the placebo group (7/108). ${ }^{31}$ The authors also investigated adverse events according to age; a greater proportion of participants over 75 years old experienced $\mathrm{OH}$ in both groups. This was $10 \%(2 / 20)$ and $3 \%(2 / 69)$ in the placebo and rotigotine group, respectively. Nicholas et al.'s study was the only study that favoured the dopamine agonist compared to placebo (Figure 3), which is probably due to small participant numbers. The authors did not include participant characteristics, such as past medical history or a medication list.

\section{Ropinirole}

One study investigated $2-24 \mathrm{mg}$ oral ropinirole in a 24 week parallel RCT with 393 participants, mean age 66 years and disease duration was 8.6 years. ${ }^{36} \mathrm{OH}$ was determined by measuring BP during 12 study visits. The incidence of $\mathrm{OH}$ events was $5 \%$ in the treatment group (11/ 202) compared to $2 \%$ in the placebo group $(3 / 191)$, but there was no significance testing.

\section{Other Antiparkinsonian Medications}

\section{COMT Inhibitors}

Two RCTs investigated $\mathrm{OH}$ in the treatment of PD by oral COMT inhibitors, in participant numbers ranging from 13750 and study duration ranging between 1 and 26 weeks. 


\begin{tabular}{|c|c|c|c|c|c|c|c|c|c|c|}
\hline \multirow{2}{*}{$\begin{array}{l}\text { Study or Subgroup } \\
\text { Hubble } 1995\end{array}$} & \multicolumn{2}{|c|}{ Experimental } & \multicolumn{2}{|c|}{ Control } & Weight & \multirow{2}{*}{$\begin{array}{c}\text { Odds Ratio } \\
\text { M-H, Fixed, } 95 \% \mathrm{Cl}\end{array}$} & Year & \multicolumn{2}{|c|}{$\begin{array}{c}\text { Odds Ratio } \\
\text { M-H, Fixed, } 95 \% \mathrm{Cl}\end{array}$} & \\
\hline & 28 & 28 & 27 & 27 & & & 1995 & & & \\
\hline Wermuth 1998 & 7 & 36 & 3 & 33 & $7.4 \%$ & $2.41[0.57,10.25]$ & 1998 & & & \\
\hline Moller 2005 & 41 & 174 & 36 & 180 & $79.9 \%$ & $1.23[0.74,2.05]$ & 2005 & & & \\
\hline Barone 2010 & 5 & 144 & 3 & 152 & $8.3 \%$ & $1.79[0.42,7.62]$ & 2010 & & & \\
\hline Schapira 2013 & 0 & 261 & 1 & 274 & $4.3 \%$ & $0.35[0.01,8.60]$ & 2013 & & & \\
\hline Total $(95 \% \mathrm{Cl})$ & & 643 & & 666 & $100.0 \%$ & $1.33[0.85,2.07]$ & & & & \\
\hline Total events & 81 & & 70 & & & & & & & \\
\hline $\begin{array}{l}\text { Heterogeneity: } \mathrm{Chi}^{2}= \\
\text { Test for overall effect }\end{array}$ & $\begin{array}{l}1.57, \mathrm{df}= \\
\mathrm{Z}=1.25\end{array}$ & $\begin{array}{l}=3(P= \\
(P=0.2\end{array}$ & $\begin{array}{l}0.67) ; 1^{2} \\
21)\end{array}$ & $=0 \%$ & & & & 0.010 .1 & $\begin{array}{c}10 \\
\text { Favours [control] }\end{array}$ & 100 \\
\hline
\end{tabular}

Figure 4. Forest plot with pramipexole studies.

Mean age was 70 years, and disease duration was 4.6 years. Limousin et al. investigated $200 \mathrm{mg}$ and $400 \mathrm{mg}$ tolcapone vs placebo ${ }^{20}$ in a crossover trial of 7 days with 13 participants and assessed lying and standing BP. Olanow et al. compared $200 \mathrm{mg}$ entacapone with placebo in a parallel trial of 26 weeks with 750 participants recording vital signs. ${ }^{21}$ The number of participants affected by $\mathrm{OH}$ was not reported in the study by Limousin et al., only the mean decrease in $\mathrm{BP}$ for the tolcapone group. The mean decrease in lying BP was $35 / 17 \mathrm{mmHg}$ and in standing BP $38 / 22 \mathrm{mmHg}$, but the authors report this decrease was similar in tolcapone and placebo groups. ${ }^{20}$ Olanow et al. found the proportion of participants with $\mathrm{OH}$ was similar in both the entacapone and placebo groups, $47 / 373(13 \%)$ and 51/377 (14\%), respectively. ${ }^{21}$ These studies suggest COMT inhibitors were not associated with an increase in $\mathrm{OH}$ compared to placebo, but the strength of evidence is low.

\section{Amantadine}

One study investigated $274 \mathrm{mg}$ oral amantadine in a 13 week parallel RCT with 77 participants, mean age 65 years and disease duration 10.4 years. ${ }^{37} \mathrm{OH}$ was determined by measuring vital signs and performing a physical examination during 9 visits. There were also safety follow up visits but is unclear if BP was measured during these. The incidence of $\mathrm{OH}$ events was $10 \%$ in the treatment group (4/37) compared to $0 \%$ in the placebo group (0/38). However, the sample size is small and the study likely underpowered.

\section{Adenosine Receptor Antagonist}

One study investigated 5-40 mg istradefylline in a 12 week parallel RCT with 83 participants, mean age was 62 years and disease duration was not reported. ${ }^{39}$ The incidence of $\mathrm{OH}$ events was $6 \%$ in the treatment group (3/54) compared to $10 \%$ in the placebo group (3/29). The strength of evidence is low, as the authors state $\mathrm{OH}$ was detected by 'adverse events at each visit', and it is unclear how BP was measured.

\section{Levodopa}

One study investigated $84 \mathrm{mg}$ inhaled levodopa in a 39 day crossover RCT with 36 participants, mean age 63 years and disease duration 7.9 years. ${ }^{38}$ Postural BP examination was performed using a threshold of $\geq 20 \mathrm{mmHg}$ systolic $\ \geq$ $10 \mathrm{mmHg}$ diastolic drop, on 2 observation days separated by an interval of 1 to 7 days. It was measured 30 mins before the dose was given and every 30 minutes for 3 hours afterwards. The incidence of $\mathrm{OH}$ events was similar, $17 \%$ in the treatment group (6/36) compared to $19 \%$ in the placebo group (7/36).

\section{Subgroup Analysis}

Two studies amongst all included studies reported a 'measured and validated' method for assessing $\mathrm{OH}$ and 2 recorded 'lying and standing BP' or 'semisupine and standing BP'. ${ }^{27,29,34,38}$ These 4 studies were therefore in the top 2 categories of $\mathrm{OH}$ reporting and included in a subgroup analysis. Limousin et al., also measured the lying and standing BP, but this was not reported for individual participants, and therefore, the data could not be included in the analysis. ${ }^{20}$ This meta-analysis found no difference in risk of $\mathrm{OH}$ between the trial medications compared with placebo (OR 1.44 [95\% CI .67-3.10]) (Figure 6).

\section{Discussion}

Our narrative synthesis did not provide conclusive evidence that $\mathrm{OH}$ incidence was greater in antiparkinsonian medication compared to placebo, and meta-analysis did not demonstrate a significant difference between MAO-B inhibitors or dopamine agonists in $\mathrm{OH}$ incidence compared to placebo. Similarly, the meta-analyses of studies of apomorphine, pramipexole and studies that were in the top 2 categories of $\mathrm{OH}$ reporting ('measured and validated', 'lying and standing measured' or 'semisupine and standing measured') did not demonstrate significant differences than the placebo group. These findings are in contrast to what is observed in clinical practice and previous observational 


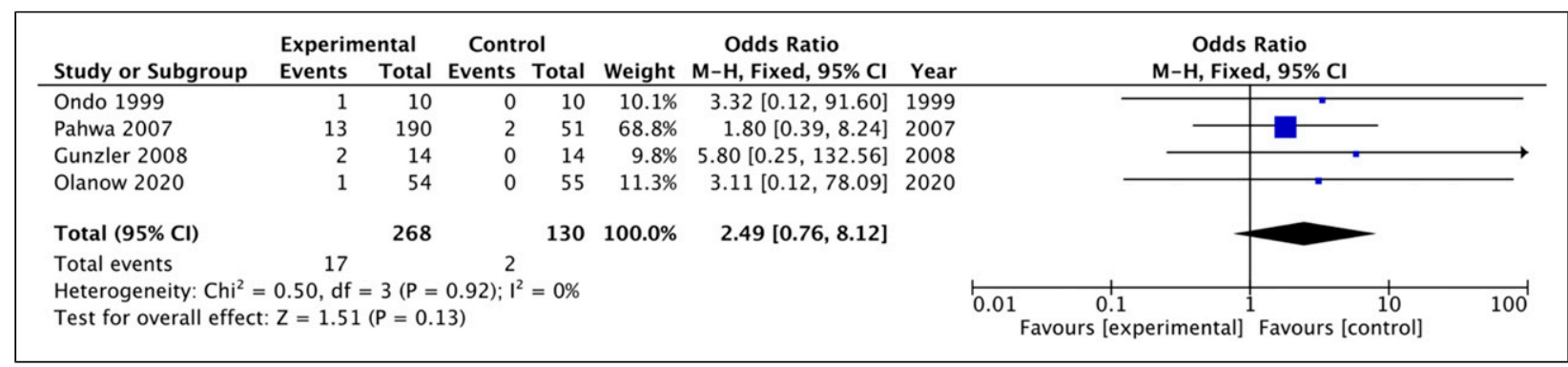

Figure 5. Forest plot with apomorphine studies.

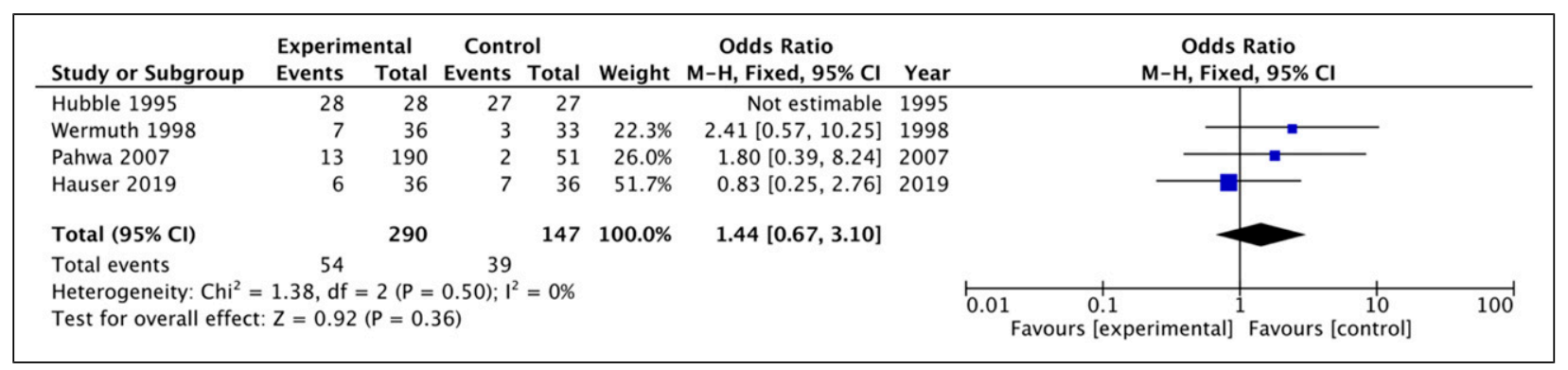

Figure 6. Subgroup analysis forest plot of studies in the top 2 categories of $\mathrm{OH}$ reporting.

studies. ${ }^{6,7}$ We believe this discrepancy is likely due to issues of poor reporting in comparison to populations studies.

Despite $\mathrm{OH}$ being a recognised complication of $\mathrm{PD}$ and its treatment, RCTs rarely used the classical definition of $\mathrm{OH}$ to report $\mathrm{OH}$. In most RCTs reporting $\mathrm{OH}$, this was recorded as an adverse event or as a measurement of vital signs. However, as $\mathrm{OH}$ is not included in the common terminology criteria for adverse events (CTCAE) system, the standard reporting method for adverse events in most clinical trials, ${ }^{41}$ many trials likely, would have reported 'dizziness' or 'hypotension'. Few trials specifically assess lying and standing $\mathrm{OH}$, and therefore, only symptomatic $\mathrm{OH}$ was likely to be reported as an adverse event. This is likely to be an underestimation of the true incidence of $\mathrm{OH}$ in $\mathrm{PD}$, particularly as the majority of $\mathrm{OH}$ in $\mathrm{PD}$ is asymptomatic. ${ }^{1}$ Many studies were small with low incidence rates that precluded significance testing. As $\mathrm{OH}$ was not the primary outcome and assessed specifically in many studies, many studies are rated as having 'some concern' or 'high' risk of bias, and the GRADE assessment was either low or very low quality.

The studies included in this systematic review may also be overrepresenting younger populations and those in the earlier stages of the disease. The average age was $57-$ 70 years old, whereas the greatest prevalence of PD is seen in people aged $70-84{ }^{42}$ This population is typical for that seen in RCTs in PD, which are often younger, as traditionally older people were underrepresented and excluded from trials despite higher rates of chronic diseases. ${ }^{43}$
Similarly, most of the trials were conducted in earlier disease stages, where $\mathrm{OH}$ is less common than in advanced stages. As both PD and ageing are associated with other risk factors for $\mathrm{OH}$, including $\mathrm{PD}$ progression, increased susceptibility to $\mathrm{OH}$ at baseline, antiparkinsonian medication, non-PD medications and comorbidities, ${ }^{4}$ the likely rate of $\mathrm{OH}$ with these medications in PD is higher. However, no study explored this complexity. Many did not describe past medical or concurrent medication history, which is important in this population.

Furthermore, the relatively low event rates and relatively short trial duration of some studies (Table 1) may have contributed to the lack of a significant finding. However, a previous meta-analysis of the efficacy and safety of non-ergot dopamine agonists in PD also found no difference in the incidence of $\mathrm{OH}$ between dopamine agonists and placebo (RR .84 [95\% CI .20-3.55]). However, this study only included data from 3 trials, and was limited by the same data limitations as this study, for example, short observation periods in some studies. ${ }^{44}$ A further study exploring the safety of ropinirole vs other dopamine agonists and levodopa explored $\mathrm{OH}$ in 665 participants and found cabergoline to be the only dopamine agonist to be associated with a higher risk of $\mathrm{OH}$ when prescribed with levodopa compared to placebo. ${ }^{12}$ Our systematic review used a broader search strategy, but theirs only searched for dopamine agonists and did not focus specifically on $\mathrm{OH}$ as an adverse outcome, which explains why they found fewer number of studies. 
A Cochrane review of RCTs evaluating the safety of adjuvant treatment to levodopa in PD reported that dopamine agonists increased the odds of hypotension (OR 1.46 [95\% 1.15, -1.84]) when compared to placebo, but COMT inhibitors and MAO-B inhibitors did not. This metaanalysis included 20 studies that recorded 'hypotension' or 'orthostatic hypotension' and the authors did not differentiate between the 2 terms. ${ }^{45}$ As mentioned above, studies are more likely to report 'hypotension' or 'dizziness' to indicate $\mathrm{OH}$, as both are common terminology criteria for adverse events (CTCAE), instead of 'orthostatic hypotension'. ${ }^{41}$ However, there are differences compared to our review. In the Cochrane review, all adverse effects were explored, while we examined $\mathrm{OH}$ specifically. They also only focused on patients who were receiving levodopa in addition to other PD medication, while our review covered all drugs used in the treatment of motor symptoms in PD. Finally, their search was conducted in 2008, and we have identified 7 new studies published since then, which are included in our review.

Some other systematic reviews and meta-analyses on PD drug safety and efficacy exploring 'hypotension' and 'dizziness' have found associations with the use of some $\mathrm{PD}$ medications and $\mathrm{OH}$. For example, a meta-analysis of 17 studies found an increased risk of hypotension when ropinirole was compared with placebo, but this was not the case for pramipexole $(6.46,95 \%$ CI $1.47-28.28$ for ropinirole and $1.65,95 \% \mathrm{CI} .88-3.08$ for pramipexole $).{ }^{46}$ However another Cochrane review exploring dopamine agonist therapy in early PD did not find an association between dopamine agonists and hypotension when compared to placebo (OR 1.73 [95\% .9-3.35]), including pooled results from 3 studies. The authors found dopamine agonists did increase the odds of developing dizziness, and these results were from 7 pooled studies (OR 1.9 [95\% 1.32-2.74]). ${ }^{47}$ This illustrates how differences in assessment of adverse side effects can lead to different conclusions.

Unlike the other studies investigating dopamine agonists, Nicholas et al. found rotigotine was protective against $\mathrm{OH}$, where $6 \%$ of the placebo and $1 \%$ of the treatment group experienced $\mathrm{OH}$, respectively. ${ }^{31}$ The participant numbers in each group ranged from 94-108 and were therefore small, which may have contributed to the result. Rotigotine stimulates dopamine $\mathrm{D}_{1}-\mathrm{D}_{3}$ receptors and transdermal application avoids the 'first pass' effect but also facilitates long acting profiles and hence systemic exposure over 24 hours. Also, plasma profiles have shown stable concentrations after multiple dosages, when applying multiple days of patches, which may possibly attenuate risk of side effects. ${ }^{48}$ Rotigotine is administered in transdermal patch formulation. Interestingly, a recent study reported the lack of clarity in the effect of route of administration on the $\mathrm{OH}$ mechanism, and therefore, further investigations are required whether rotigotine's effects could be attributed to transdermal delivery. ${ }^{49}$

Furthermore, a recent drug vs drug vs placebo RCT compared ropinirole, rotigotine and placebo and found the incidence of $\mathrm{OH}$ to be $7 / 167$ (4.2\%), 5/168 (3\%) and 4/85 (4.7\%), respectively, where $\mathrm{OH}$ was reported less frequently in the rotigotine group compared to placebo. ${ }^{50}$ These results were not significant as $P$ values were $>.5$, and therefore support our overall findings.

\section{Strengths and Limitations}

Strengths of this review include a comprehensive literature search aided by an information scientist and according to published guidelines. ${ }^{14}$ There was also substantial agreement between reviewers, and a broad multidisciplinary team was involved in the interpretation of results, including primary care physicians, a neurologist and pharmacist. However, our systematic review only explored placebo vs drug studies, not drug vs drug RCTs, which tend to be more recent and would have provided additional data. As discussed above, we searched for studies specifically mentioning $\mathrm{OH}$, rather than terms that might suggest presence of $\mathrm{OH}$, which is likely to have led to an underestimation of the rate of $\mathrm{OH}$, highlighting the need to specifically assess $\mathrm{OH}$ in clinical trials of medications reported to be associated with this adverse effect. Furthermore, the RCTs rarely included patients with more advanced disease and multiple other medications that may contribute to $\mathrm{OH}$.

\section{Future Research and Implications}

As generally acknowledged, RCTs should strive to include a study population that truly represents the PD population, including older participants ( $>75$ years old), those with multimorbidity and longer disease duration. Reporting of adverse event studies need to adhere to standard reporting frameworks and additional reporting of adverse events that are particularly relevant to the $\mathrm{PD}$ population, such as $\mathrm{OH}$, should also be included in reporting adverse events in future PD trials.

\section{Conclusion}

In this systematic review and meta-analysis of RCTs reporting $\mathrm{OH}$ in antiparkinsonian medications, these drugs were not significantly associated with an increased risk of $\mathrm{OH}$ compared to placebo. However, the limitations in reporting $\mathrm{OH}$ and the populations included are likely to have resulted in an underestimation of this potential adverse effect. 


\section{Author Contributions}

All authors contributed substantially to the conception, design of the work, analysis, and interpretation of data for the work; drafted the work or revised it critically for important intellectual content. All approved the final version to be published; and agree to be accountable for all aspects of the work in ensuring that questions related to the accuracy or integrity of any part of the work are appropriately investigated and resolved.

\section{Declaration of Conflicting Interests}

The author(s) declared no potential conflicts of interest with respect to the research, authorship, and/or publication of this article.

\section{Funding}

The author(s) disclosed receipt of the following financial support for the research, authorship, and/or publication of this article: Danielle Nimmons is an In-Practice Fellow supported by the Department of Health and Social Care and the National Institute for Health Research.

\section{ORCID iD}

Danielle Nimmons (D) https://orcid.org/0000-0002-1239-3417

\section{References}

1. Velseboer DC, de Haan RJ, Wieling W, Goldstein DS, de Bie RMA. Prevalence of orthostatic hypotension in parkinson's disease: a systematic review and meta-analysis. Park Relat Disord. 2011;17:724-729. DOI: 10.1016/j.parkreldis.2011. 04.016 .

2. Freeman R, Wieling W, Axelrod FB, et al. Consensus statement on the definition of orthostatic hypotension, neurally mediated syncope and the postural tachycardia syndrome. Clin Auton Res. 2011;21:69-72. DOI: 10.1007/ s10286-011-0119-5.

3. Freeman R, Abuzinadah AR, Gibbons C, Jones P, Miglis MG, Sinn DI. Orthostatic hypotension. J Am Coll Cardiol. 2018;72:1294-1309. https://doi.org/https://doi.org/10.1016/ j.jacc.2018.05.079

4. Brignole M, Moya A, de Lange FJ, et al. Practical instructions for the 2018 ESC guidelines for the diagnosis and management of syncope. Eur Heart J. 2018;39:e43-1948. DOI: 10.1093/eurheartj/ehy037.

5. Udow SJ, Robertson AD, MacIntosh BJ, et al. 'Under pressure': is there a link between orthostatic hypotension and cognitive impairment in $\alpha$-synucleinopathies? J Neurol Neurosurg Psychiatr. 2016;87(12):1311-1321. doi:10.1136/jnnp-2016-314123. Epub 2016 Sep 9. PMID: 27613160.

6. Noack C, Schroeder C, Heusser K, Lipp A. Cardiovascular effects of levodopa in parkinson's disease. Park Relat Disord. 2014;20:815-818. doi:10.1016/j.parkreldis.2014.04.007.
7. Calne DB, Brennan J, Spiers ASD, Stern GM. Hypotension caused by L-dopa. Bmj. 1970;1:474-475. doi:10.1136/bmj. 1.5694.474.

8. Parkes JD. Adverse effects of antiparkinsonian drugs. Drugs. 1981;21:341-353. doi:10.2165/00003495-198121050-00002.

9. Milon D, Allain H, Reymann J, Morel G, Sabouraud O, Driessche J. Randomized double-blind trial of injectable heptaminol for controlling spontaneous or bromocriptine-induced orthostatic hypotension in parkinsonians. Fund Clin Pharmacol. 1990;4:695-705. doi:10.1111/j.1472-8206.1990.tb00049.x.

10. Schoenberger JA. Drug-induced orthostatic hypotension. Drug Saf. 1991;6:402-407. doi:10.2165/00002018-199106060-00002.

11. Heinonen EH, Myllylä V. Safety of selegiline (deprenyl) in the treatment of parkinson's disease. Drug Saf. 1998;19: 11-22. doi:10.2165/00002018-199819010-00002.

12. Kulisevsky J, Pagonabarraga J. Tolerability and safety of ropinirole versus other dopamine agonists and levodopa in the treatment of parkinson's disease. Drug Saf. 2010;33: 147-161. doi:10.2165/11319860-000000000-00000.

13. Freemantle N, Marston L, Walters K, Wood J, Reynolds MR, Petersen I. Making inferences on treatment effects from real world data: propensity scores, confounding by indication, and other perils for the unwary in observational research. BMJ (Clinical research ed.). 2013;347:f6409. doi: 10.1136/bmj.f6409.

14. Moher D, Liberati A, Tetzlaff J, Altman DG. Preferred reporting items for systematic reviews and meta-analyses: the PRISMA statement. Ann Intern Med. 2009;151:264-269. doi:10.7326/0003-4819-151-4-200908180-00135.

15. York University. Prospero. 2020. https://www.crd.york.ac. uk/prospero/display_record.php?ID=CRD42020168697 (accessed Apri 04, 21)

16. University of Oxford. EBM datalab, (n.d.). https:// openprescribing.net/ (accessed November 28, 2020).

17. Ouzzani M, Hammady H, Fedorowicz Z, Elmagarmid A. Rayyan-a web and mobile app for systematic reviews. Syst Rev. 2016;5:210. doi:10.1186/s13643-016-0384-4.

18. Sterne JAC, Savović J, Page MJ, et al. RoB 2: a revised tool for assessing risk of bias in randomised trials. BMJ. 2019 366:14898. doi:10.1136/bmj.14898.

19. Guyatt GH, Oxman AD, Vist GE, et al. GRADE: an emerging consensus on rating quality of evidence and strength of recommendations. BMJ. 2008;336:924-926. doi: 10.1136/bmj.39489.470347.AD.

20. Limousin P, Pollak P, Pfefen JP, Tournier-Gervason CL, Dubuis R, Perret JE. Acute administration of levodopabenserazide and tolcapone, a COMT inhibitor, parkinson's disease. Clin Neuropharmacol. 1995;18:258-265. https:// journals.lww.com/clinicalneuropharm/Fulltext/1995/06000/ Acute_Administration_of_Levodopa_Benserazide_and.6.aspx

21. Olanow CW, Kieburtz K, Stern M, et al. Double-blind, placebo-controlled study of entacapone in levodopa-treated patients with stable parkinson disease. Arch Neurol. 2004;61: 1563-1568. doi:10.1001/archneur.61.10.1563. 
22. Takahashi M, Yuasa R, Yuasa R, et al. Selegiline (LDeprenyl) and L-dopa treatment of parkinson's disease: a double-blind trial. Intern Med. 1994;33:517-524. doi:10. 2169/internalmedicine.33.517.

23. Presthus J, Hajba A. Deprenyl (selegiline) combined with levodopa and a decarboxylase inhibitor in the treatment of parkinson's disease. Acta Neurol Scand. 1983;68:127-133. doi:10.1111/j.1600-0404.1983.tb01527.x

24. Brodersen P, Philbert A, Gulliksen G, Stigård A. The effect of L-deprenyl on on-off phenomena in parkinson's disease. Acta Neurologica Scandinavica. 1985;71:494-497. doi:10. 1111/j.1600-0404.1985.tb03233.x.

25. Weintraub D, Hauser RA, Elm JJ, Pagan F, Davis MD, Choudhry A, for the M. Investigators, Rasagiline for mild cognitive impairment in Parkinson's disease: A placebocontrolled trial. Mov Disord. 31 (2016) 709-714. doi:10. 1002/mds. 26617

26. Möller JC, Oertel WH, Köster J, Pezzoli G, Provinciali L. Long-term efficacy and safety of pramipexole in advanced Parkinson's disease: Results from a European multicenter trial. Mov Disord. 2005;20:602-610. doi:10.1002/mds.20397.

27. Hubble JP, Koller WC, Cutler NR, et al. Pramipexole in patients with early parkinson's disease. Clin Neuropharmacol. 1995;18:338-347. https://journals.lww.com/clinicalneuropharm/ Fulltext/1995/08000/Pramipexole_in_Patients_with_Early_ Parkinson_s.6.aspx

28. Schapira AH, McDermott MP, Barone P, et al. Pramipexole in patients with early parkinson's disease (PROUD): a randomised delayed-start trial. Lancet Neurol. 2013;12: 747-755. doi:10.1016/S1474-4422(13)70117-0.

29. Wermuth L. A double-blind, placebo-controlled, randomized, multi-center study of pramipexole in advanced parkinson's disease. Eur J Neurol. 1998;5:235-242. http://ovidsp.ovid.com/ ovidweb.cgi? $\mathrm{T}=\mathrm{JS} \& \mathrm{PAGE}=$ reference $\& \mathrm{D}=$ medp $\& \mathrm{NEWS}=$ $\mathrm{N} \& \mathrm{AN}=10210837$

30. Barone P, Poewe W, Albrecht S, et al. Pramipexole for the treatment of depressive symptoms in patients with parkinson's disease: a randomised, double-blind, placebo-controlled trial. Lancet Neurol. 2010;9:573-580. doi:10.1016/S14744422(10)70106-X.

31. Nicholas AP, Borgohain R, Chaná P, Surmann E, Thompson EL, Bauer L, et al. A Randomized Study of Rotigotine Dose Response on 'Off' Time in Advanced Parkinson's Disease. $J$ Parkinsons Dis. 2014;4:361-373. doi:10.3233/JPD-130320.

32. Hutton JT, Metman LV, Chase TN, et al. Transdermal dopaminergic D 2 receptor agonist therapy in parkinson's disease with N-0923 TDS: a double-blind, placebo-controlled study. Mov Disord. 2001;16:459-463. doi:10.1002/mds.1085.

33. Gunzler SA, Koudelka C, Carlson NE, Pavel M, Nutt JG. Effect of low concentrations of apomorphine on parkinsonism in a randomized, placebo-controlled, crossover study. Arch Neurol. 2008;65:193-198. doi:10.1001/archneurol.2007.58.

34. Pahwa R, Koller WC, Trosch RM, Sherry JH. Subcutaneous apomorphine in patients with advanced parkinson's disease: a dose-escalation study with randomized, double-blind, placebo-controlled crossover evaluation of a single dose. J Neurol Sci. 2007;258:137-143. doi:10.1016/j.jns.2007.03. 013.

35. Ondo W, Hunter C, Almaguer M, Gancher S, Jankovic J. Efficacy and tolerability of a novel sublingual apomorphine preparation in patients with fluctuating parkinson's disease. Clin Neuropharmacol. 1999;22:1-4. https://journals.lww.com/ clinicalneuropharm/Fulltext/1999/01000/Efficacy_and_ Tolerability_of_a_Novel_Sublingual.1.aspx

36. Pahwa R, Stacy MA, Factor SA, et al. Ropinirole 24-hour prolonged release: randomized, controlled study in advanced parkinson disease. Neurology. 2007;68:1108-1115. doi:10.1212/01.wnl.0000258660.74391.c1.

37. Oertel W, Eggert K, Pahwa R, et al. Randomized, placebocontrolled trial of ADS-5102 (amantadine) extended-release capsules for levodopa-induced dyskinesia in parkinson's disease (EASE LID 3). Mov Disord. 2017;32:1701-1709. doi:10.1002/mds.27131.

38. Hauser RA, Isaacson SH, Ellenbogen A, et al. Orally inhaled levodopa (CVT-301) for early morning OFF periods in parkinson's disease. Park Relat Disord. 2019;64:175-180. doi:10.1016/j.parkreldis.2019.03.026.

39. Hauser RA, Hubble JP, Truong DD. Randomized trial of the adenosine A2Areceptor antagonist istradefylline in advanced PD. Neurology. 2003;61:297-303. doi:10.1212/01. WNL.0000081227.84197.0B.

40. Olanow CW, Factor SA, Espay AJ, et al. Apomorphine sublingual film for off episodes in parkinson's disease: a randomised, double-blind, placebo-controlled phase 3 study. Lancet Neurol. 2020;19:135-144. doi:10.1016/S14744422(19)30396-5.

41. Trotti A, Colevas A, Setser A, et al. CTCAE v3.0: development of a comprehensive grading system for the adverse effects of cancer treatment. Semin Radiat Oncol. 2003;13: 176-181. doi:10.1016/S1053-4296(03)00031-6.

42. Parkinson's UK. The incidence and prevalence of parkinson's in the UK. 2018. https://www.parkinsons.org.uk/sites/ default/files/2018-01/CS2960. Incidence and prevalence report branding summary report.pdf.

43. Herrera AP, Snipes SA, King DW, Torres-Vigil I, Goldberg DS, Weinberg AD. Disparate inclusion of older adults in clinical trials: priorities and opportunities for policy and practice change. Am J Publ Health. 2010;100(Suppl 1): S105-S112. doi:10.2105/AJPH.2009.162982.

44. Zhou C-Q, Zhang J-W, Wang M, Peng G-G. Meta-analysis of the efficacy and safety of long-acting non-ergot dopamine agonists in parkinson's disease. J Clin Neurosci. 2014;21: 1094-1101. doi:10.1016/j.jocn.2013.10.041.

45. Stowe R, Ives N, Clarke CE, Deane K. et al. Evaluation of the efficacy and safety of adjuvant treatment to levodopa therapy in Parkinson's disease patients with motor complications. Cochrane Database Syst Rev. 2010;7:CD007166. doi:10.1002/14651858.CD007166.pub2. 
46. Etminan M, Gill S, Samii A. Comparison of the risk of adverse events with pramipexole and ropinirole in patients with parkinson's disease. Drug Saf. 2003;26:439-444. doi: 10.2165/00002018-200326060-00005.

47. Stowe R, Ives N, Clarke CE. et al. Dopamine agonist therapy in early parkinson's disease. Cochrane Database Syst Rev. 2008; 16:CD006564. doi:10.1002/14651858.CD006564.pub2.

48. Elshoff J-P, Cawello W, Andreas J-O, Mathy F-X, Braun M. An update on pharmacological, pharmacokinetic properties and drug-drug interactions of rotigotine transdermal system in parkinson's disease and restless legs syndrome. Drugs. 2015;75:487-501. doi:10.1007/s40265-015-0377-y.

49. Kiuchi S, Hisatake S, Kabuki T, et al. Bisoprolol transdermal patch improves orthostatic hypotension in patients with chronic heart failure and hypertension. Clin Exp Hypertens. 2020;42:539-544. doi:10.1080/10641963.2020.1723616.

50. Mizuno Y, Nomoto M, Hasegawa K, et al. Rotigotine vs ropinirole in advanced stage parkinson's disease: a doubleblind study. Park Relat Disord. 2014;20:1388-1393. doi:10. 1016/j.parkreldis.2014.10.005. 


\section{Appendix I}

\section{Search Strategy.}

Search Strategy Example (Medline).

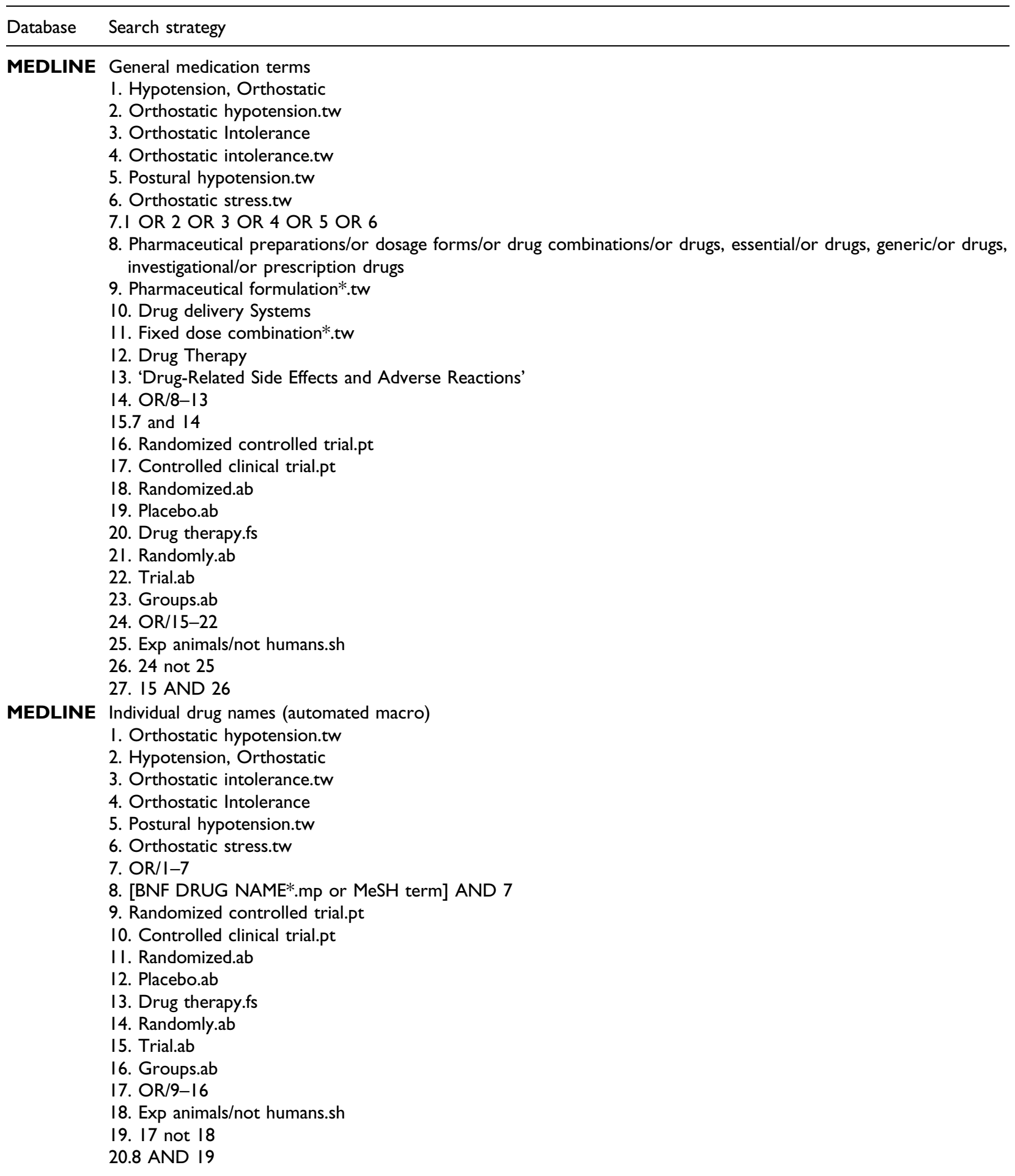




\section{Appendix 2}

\section{Risk of Bias.}

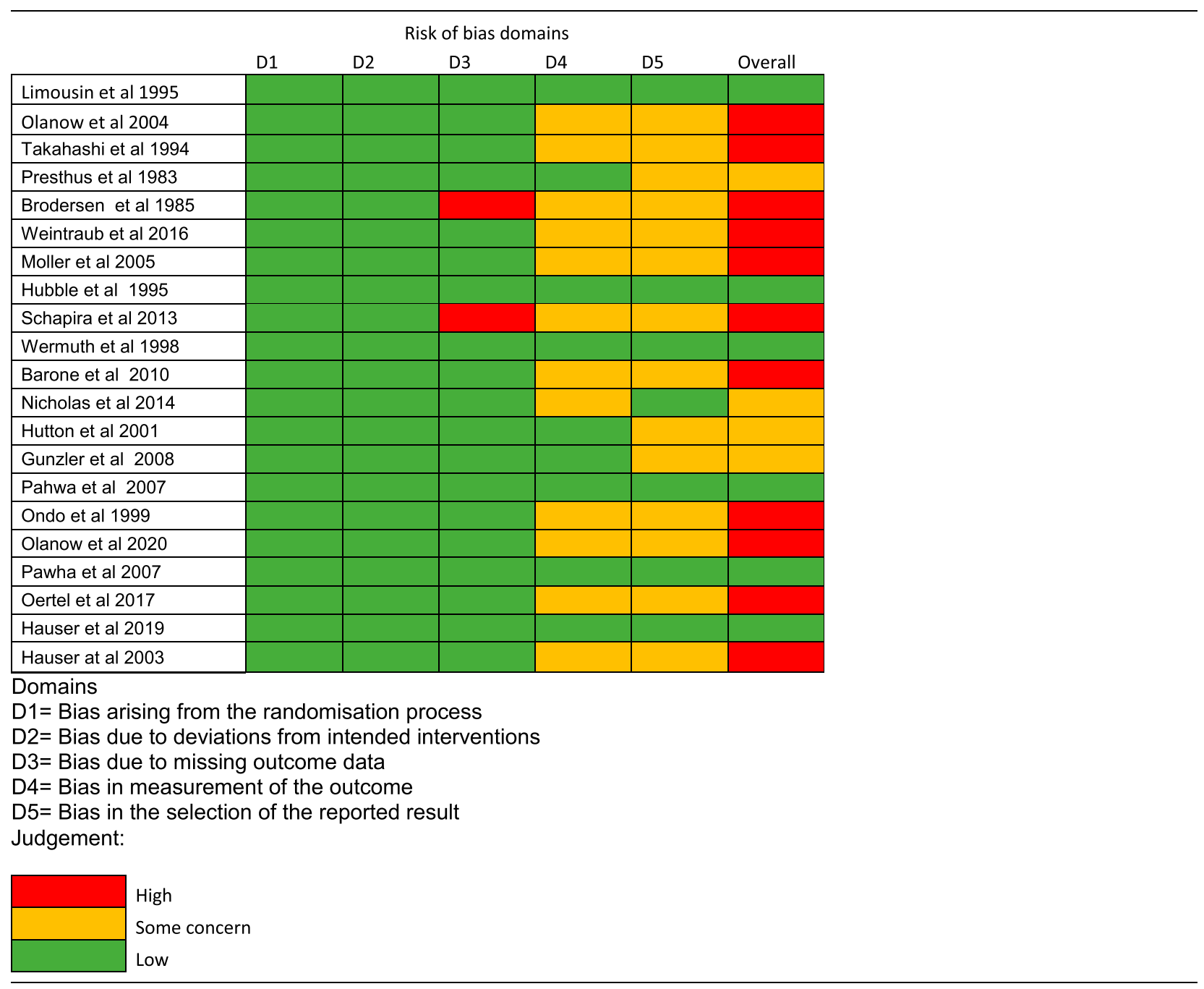




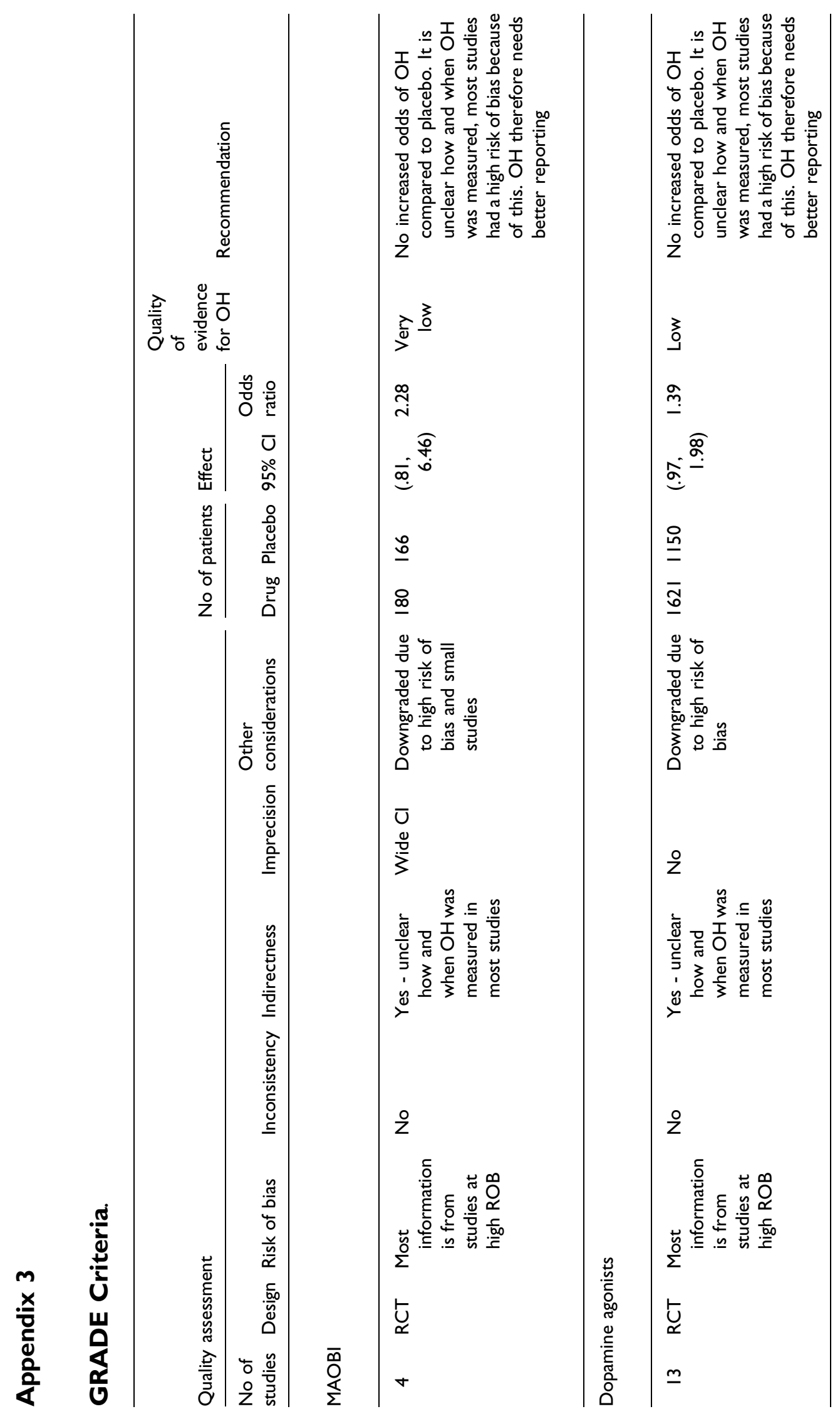

